\title{
Pengaruh Ketebalan Komposit Serat Sabut Kelapa terhadap Koefisien Absorbsi Bunyi dan Impedansi Akustik Menggunakan Metode Tabung Impedansi
}

\author{
Ya Putri*, Elvaswer \\ Jurusan Fisika FMIPA Universitas Andalas Kampus Unand, Limau Manis, Padang, 25163 \\ *yaputri54@gmail.com
}

\begin{abstract}
ABSTRAK
Penelitian ini dilakukan untuk mengetahui pengaruh ketebalan komposit serat sabut kelapa terhadap koefisien absorbsi bunyi dan impedansi akustik menggunakan metode tabung impedansi. Sampel dibuat dengan variasi ketebalan $0,25 \mathrm{~cm}, 0,5 \mathrm{~cm}, 0,75 \mathrm{~cm}, 1 \mathrm{~cm}$ dan $1,25 \mathrm{~cm}$ dengan rentang frekuensi yang digunakan adalah 500, 1000, 1500, 2000, dan $2500 \mathrm{~Hz}$. Nilai koefisien absorbsi bunyi terendah sebesar 0,44 terdapat pada ketebalan $0,25 \mathrm{~cm}$ dengan frekuensi $1500 \mathrm{~Hz}$. Nilai koefisien absorbsi bunyi tertinggi sebesar 0,92 terdapat pada sampel dengan ketebalan $1,25 \mathrm{~cm}$ dengan frekuensi $2500 \mathrm{~Hz}$. Hal ini disebabkan karena gelombang bunyi pada frekuensi yang lebih tinggi lebih banyak bervibrasi melalui pori-pori yang ada pada sampel daripada dipantulkan. Nilai impedansi akustik terendah sebesar 0,569 dyne.sekon/cm berada pada frekuensi $500 \mathrm{~Hz}$ dengan ketebalan $0.25 \mathrm{~cm}$. Nilai dari impedansi akustik tertinggi 2,485 dyne.sekon/cm berada pada frekuensi $2500 \mathrm{~Hz}$ dengan ketebalan sampel 1,25 cm. Hal ini disebabkan oleh impedansi akustik berbanding lurus dengan induktansi dimana pada material akustik analog dengan massa.

Kata kunci: komposit serat sabut kelapa, koefisien absorbsi bunyi, impedansi akustik, metode tabung impedansi
\end{abstract}

\begin{abstract}
The research about influence of coconut fiber composite thickness to sound absorption coefficient and acoustic impedance by using impedance tube method has been done. The sample was made by thickness variation of $0,25 \mathrm{~cm}, 0,5 \mathrm{~cm}, 0,75 \mathrm{~cm}, 1 \mathrm{~cm}$ and $1,25 \mathrm{~cm}$ with frequency range of $500,1000,1500,2000$, and $2500 \mathrm{~Hz}$. The lowest sound absorption of coefficient is 0,44 at thickness of $0,25 \mathrm{~cm}$ at frequency of $1500 \mathrm{~Hz}$. The highest sound absorption coefficient is 0,92 at thickness of $1,25 \mathrm{~cm}$ at frequency of 2500 $\mathrm{Hz}$. This was because sound waves at higher frequency vibrate more in pores than being reflected. The lowest acoustic impedance is 0,569 dyne.second/cm at a frequency of $500 \mathrm{~Hz}$ with a sample thickness of $0,25 \mathrm{~cm}$. The highest acoustic impedance is 2,485 dyne.second/cm at a frequency of $2500 \mathrm{~Hz}$ with a sample thickness of $1,25 \mathrm{~cm}$. This is due to the acoustic impedance being directly proportional to the inductance in which the acoustic material is analogous to the mass.

Keywords: coconut fiber composite, sound absorption coefficient, acoustic impedance, impedance tube method
\end{abstract}

\section{PENDAHULUAN}

Bunyi adalah gejala fisis utama yang digunakan untuk berkomunikasi. Namun komunikasi dapat terganggu dengan adanya bunyi lain atau yang disebut dengan gema. Gema sering timbul pada ruang yang tertutup atau ruang yang membentuk suatu dinding yang mengisolasi. Gema timbul karena adanya selisih waktu terdengarnya bunyi asli dengan bunyi pantul. Gema tersebut menimbulkan kebisingan sehingga dapat menyebabkan gangguan pada kenyamanan telinga seseorang.

Walaupun suara yang lemah dapat didengar dalam ruang yang sunyi, namun untuk mengerti suara yang keras sekali pun di sekitar deru mesin pesawat terbang tentunya sulit. Gema, pemantulan yang berkepanjangan, dan gaung dapat dicegah dengan memasang bahan penyerap bunyi pada permukaan pemantul. Bahan penyerap bunyi dapat digunakan untuk mengurangi kebisingan yang terjadi di dalam ruangan. Bahan yang banyak digunakan sebagai penyerap dan peredam bunyi antara lain glasswool, rockwool, dan bahan segneselulosa. Biasanya bahan yang mengandung segneselulosa digunakan sebagai bahan dasar untuk pembuatan peredam bunyi, salah satunya adalah serat sabut kelapa (Bucur, 2006).

Elkhateeb (2016), dalam penelitiannya mengenai pengukuran koefisien absorbsi bunyi pada bahan organik karpet masjid, menyimpulkan bahwa koefisien absorbsi bunyi optimal pada rentang frekuensi $2000 \mathrm{~Hz}$ yaitu 0,76. Koefisien absorbsi bunyi dipengaruhi oleh ketinggian 
tumpukan karpet. Bantalan meningkatkan batas serapan dari hamparan pada daerah-frekuensi pertengahan, dan beberapa akibat juga tampak pada daerah-frekuensi rendah dan tinggi.

Puspitarini (2014), dalam penelitiannya mengenai koefisien absorbsi bunyi ampas tebu sebagai bahan peredam suara menunjukkan bahwa koefisien absorbsi bunyi pada sampel dengan ketebalan $0,26 \mathrm{~cm}, 0,48 \mathrm{~cm}, 0,76 \mathrm{~cm}$ berturut-turut adalah $0,7,0,6$, dan 0,5 pada frekuensi $400 \mathrm{~Hz}$. Berbagai penelitian yang telah dilakukan sebelumnya, untuk dapat meningkatkan nilai koefisien absorbsi bunyi maka dipilihlah bahan berserat alami dengan memvariasikan ketebalan pada sampel.

Tujuan dari penelitian ini adalah mengetahui pengaruh ketebalan komposit serat sabut kelapa terhadap koefisien absorbsi bunyi dan impedansi akustik menggunakan metode tabung impedansi. Mengetahui pengaruh frekuensi terhadap koefisien absorbsi bunyi. Metode yang digunakan adalah metode tabung impedansi. Karena metode tabung impedansi lebih sesuai dengan teoritis dan analisis.

Pada penelitian ini bahan organik yang digunakan yaitu serat sabut kelapa. Alasan menggunakan serat sabut kelapa karena merupakan material berpori dengan kandungan bahan organik seperti yang telah dilakukan pada penelitian sebelumnya. Dengan memperoleh nilai koefisien absorbsi bunyi maka hasil nantinya dapat dibandingkan dengan penelitian sebelumnya mana komposit yang lebih optimal dalam menyerap bunyi.

Matriks dalam komposit berfungsi sebagai bahan mengikat serat menjadi sebuah unit struktur, melindungi dari kerusakan eksternal, meneruskan atau memindahkan beban eksternal pada bidang geser antara serat dan matriks, sehingga matriks dan serat saling berhubungan (Matthews dan Rawlings, 1993). Pembuatan komposit serat membutuhkan ikatan permukaan yang kuat antara serat dan matriks. Selain itu, matriks juga harus mempunyai kecocokan secara kimia agar reaksi yang tidak diinginkan tidak terjadi pada permukaan kontak antara keduanya. Pemilihan matriks harus diperhatikan sifat-sifatnya terlebih dahulu. Salah satu yang digunakan dalam pembuatan komposit adalah semen. Semen adalah bahan perekat hidrolis-anorganik berbentuk powder halus yang mempunyai sifat pengikatan kimia adhesif, kohesif dan dapat membentuk senyawa baru pasta hingga padatan, bila direaksikan dengan air dalam waktu tertentu.

\section{METODE}

\subsection{Pembuatan Komposit Serat Sabut Kelapa}

Serat sabut kelapa dicuci bersih dengan air terlebih dahulu, kemudian dikeringkan di udara terbuka dengan bantuan sinar matahari selama 5 hari. Selanjutnya serat sabut kelapa dimasukkan ke dalam oven dengan temperatur $70^{\circ} \mathrm{C}$ selama 2 jam untuk menghilangkan kadar air yang ada pada serat. Kemudian serat sabut kelapa dipotong dengan ukuran $1 \mathrm{~cm}$. Selanjutnya matriks (beton) dibuat dengan komposisi $200 \mathrm{~g}$ pasir, $100 \mathrm{~g}$ semen dan $250 \mathrm{~mL}$ air, semuanya diaduk sampai homogen. Setelah itu serat sabut kelapa sebanyak 150 gr dimasukkan ke dalam matriks yang telah homogen. Setelah itu komposit dimasukkan ke dalam cetakan masingmasing 1 sampel dengan ketebalan $0,25 \mathrm{~cm}, 0,5 \mathrm{~cm}, 0,75 \mathrm{~cm}, 1 \mathrm{~cm}$ dan $1,25 \mathrm{~cm}$. Setelah itu komposit dikeringkan dengan cahaya matahari selama 2 hari.

\subsection{Pengambilan Data}

Pengambilan data untuk memperoleh nilai koefisien absorbsi bunyi dan impedansi akustik dilakukan dengan metode tabung impedansi. Langkah selanjutnya yaitu dirangkainya alat-alat yang diperlukan seperti loudspeaker, tabung impedansi, mikrofon, amplifier, sinyal generator, dan osiloskop seperti Gambar 1. Sebelum digunakan osiloskop dikalibrasi terlebih dahulu agar gelombang yang kita dapatkan tidak ada noise. 


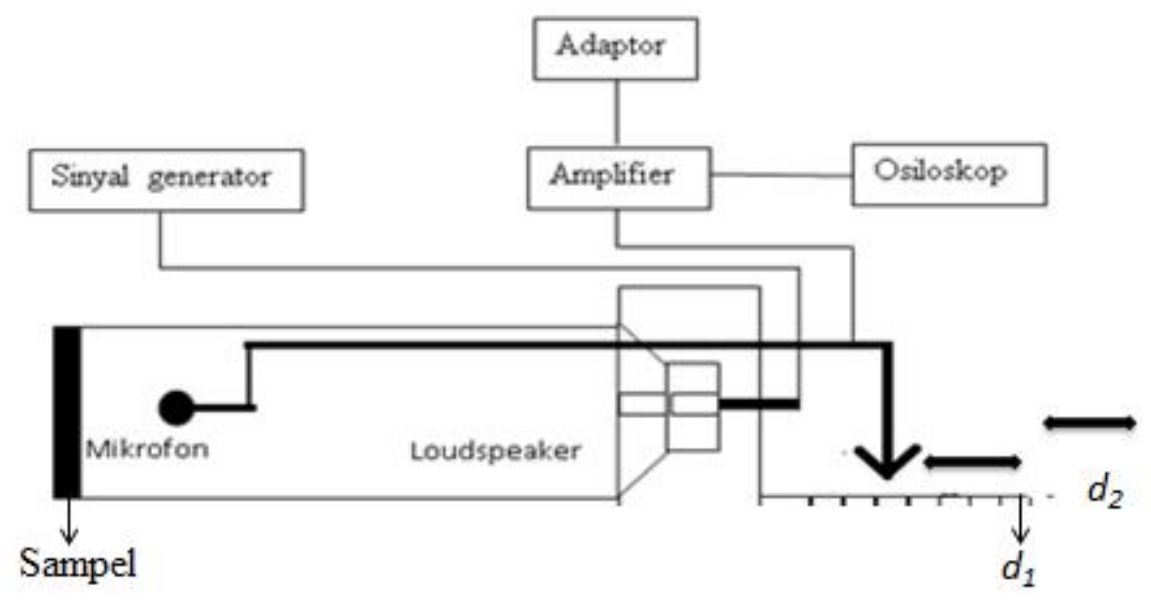

Gambar 1 Setting peralatan metode tabung impedansi

Pada salah satu ujung tabung diletakkan loudspeaker dan pada ujung tabung yang lain diletakkan sampel yang akan diuji nilai koefisien absorbsinya. Mikrofon diletakkan ditengahtengah diameter tabung ke arah sampel. Pada ujung mikrofon diletakkan sebuah kawat sehingga dapat digeser.

Untuk menentukan amplitudo tekanan maksimum $(A+B)$ dan amplitudo tekanan minimum $(A-B)$ mikrofon digeser menjauhi sampel sehingga osiloskop menunjukkan puncak gelombang tertinggi yang dilambangkan dengan amplitudo tekanan maksimum $(A+B)$.

$$
A+B=\text { Amplitudo }_{\text {maks }} \times \mathrm{V} \times \text { probe }
$$

dimana $V$ itu tegangan yang tertera pada osiloskop. Amplitudo ${ }_{\max }$ merupakan jumlah kotak pada puncak gelombang tertinggi yang terlihat pada osiloskop. Probe merupakan besar penguatan yang diatur pada pengkalibrasian osiloskop. Kemudian mikrofon digeser lagi menjauhi sampel sehingga tampilan osiloskop menunjukkan puncak gelombang terpendek yang dilambangkan dengan amplitudo tekanan minimum $(A-B)$ dan dilakukan pengukuran.

$$
A-B=\text { Amplitudo }_{\text {min }} \mathrm{x} V \mathrm{x} \text { probe }
$$

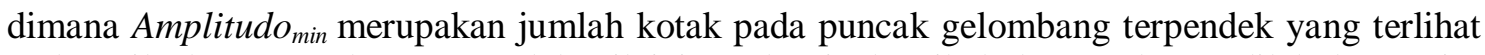
pada osiloskop. Untuk memperoleh nilai impedansi akustik hal yang harus dilakukan yaitu mikrofon digeser menjauhi sampel hingga menunjukkan jarak amplitudo minimum pertama $\left(d_{l}\right)$, caranya yaitu dengan melihat tekanan amplitudo minimum pada osiloskop lalu lihat ke meteran yang ada di dekat tabung impedansi maka nilai meteran itulah yang disebut jarak amplitudo minimum pertama $\left(d_{l}\right)$. Kemudian mikrofon digeser lagi menjauhi sampel sehingga menunjukkan jarak amplitudo minimum kedua $\left(d_{2}\right)$ yang diukur pada skala jarak. Pengambilan data pada sampel pertama dilakukan 6 kali pengulangan. Pengukuran koefisien absorbsi bunyi dan impedansi material akustik untuk masing-masing frekuensi dilakukan sebanyak 3 kali pengambilan data.

\subsection{Pengolahan Data}

Data yang diperoleh setelah melakukan pengukuran dengan metode tabung selanjutnya diolah. Nilai koefisien absorbsi bunyi diperoleh dari amplitudo tekanan maksimum dan amplitudo tekanan minimum. Perbandingan antara amplitudo tekanan maksimum dengan amplitudo tekanan minimum disebut dengan rasio gelombang tegak (SWR), yang secara matematis dapat dituliskan oleh persamaan :

$$
S W R=\frac{A+B}{A-B}
$$

Langkah selanjutnya yaitu menghitung nilai koefisien absorbsi bunyi $(\alpha)$ dengan persamaan : 


$$
\alpha=1-\left(\frac{S W R-}{S W R+1}\right)^{2}
$$

Selanjutnya nilai impedansi akustik dihitung dari persamaan di bawah ini :

$$
\begin{gathered}
\psi_{1}=\operatorname{coth}^{-1}\left(\log _{10}(S W R / 20)\right. \\
\psi_{2}=\pi\left(\frac{1}{2}-\frac{d_{1}}{d_{2}}\right) \\
Z_{s}=\operatorname{coth}\left(\psi_{1}+j \psi_{2}\right)
\end{gathered}
$$

dimana $\psi_{1}+j \psi_{2}$ merupakan besaran kompleks yang berasosiasi dengan kondisi refleksi pada permukaan sampel uji. Kemudian hasil dari persamaan di atas di mutlakkan

$$
\left|Z_{s}\right|=\operatorname{coth} \sqrt{\left(\psi_{1}\right)^{2}+\left(\psi_{2}\right)^{2}}
$$

\section{HASIL DAN DISKUSI}

\subsection{Hubungan Ketebalan Sampel terhadap Koefisien Absorbsi Bunyi}

Nilai koefisien absorbsi bunyi dengan variasi ketebalan komposit serat sabut kelapa dan variasi frekuensi dapat dilihat pada Tabel 1. Dari Tabel 1 dapat dilihat bahwa untuk kelima sampel uji nilai koefisien absorbsi bunyi tertinggi berada pada frekuensi $2500 \mathrm{~Hz}$ dengan ketebalan $1,25 \mathrm{~cm}$ sebesar 0,92 . Hal ini disebabkan karena semakin banyaknya pori-pori terbentuk akibat dari percampuran antara pasir, semen, air, dan serat sabut kelapa yang menyebabkan banyaknya bunyi yang masuk ke dalam pori-pori sehingga terjadi resonansi di dalam pori-pori yang mengakibatkan gelombang bunyi terserap oleh komposit serat sabut kelapa. Pada sampel dengan ketebalan $0,25 \mathrm{~cm}$ memiliki nilai koefisien absorbsi bunyi terendah sebesar 0,44. Hal ini disebabkan karena semakin sedikitnya pori-pori terbentuk pada percampuran antara pasir, semen, air, dan serat sabut kelapa yang menyebabkan sedikitnya bunyi yang masuk ke dalam pori-pori. Ketebalan komposit serat sabut kelapa sangat mempengaruhi nilai koefisien absorbsi bunyi.

Tabel 1 Nilai Koefisien Absorbsi Bunyi $(\alpha)$

\begin{tabular}{cccccc}
\hline \multirow{2}{*}{ Frekuensi (Hz) } & \multicolumn{5}{c}{ Ketebalan / Koefisien Absorbsi Bunyi } \\
\cline { 2 - 6 } & $\mathbf{0 , 2 5} \mathbf{~ c m}$ & $\mathbf{0 , 5} \mathbf{~ c m}$ & $\mathbf{0 , 7 5} \mathbf{~ c m}$ & $\mathbf{1 ~ c m}$ & $\mathbf{1 , 2 5} \mathbf{~ c m}$ \\
\hline 500 & 0,58 & 0,62 & 0,65 & 0,70 & 0,80 \\
1000 & 0,60 & 0,65 & 0,68 & 0,72 & 0,78 \\
1500 & 0,44 & 0,50 & 0,60 & 0,65 & 0,83 \\
2000 & 0,60 & 0,70 & 0,74 & 0,78 & 0,81 \\
2500 & 0,70 & 0,75 & 0,80 & 0,88 & 0,92 \\
\hline
\end{tabular}

Grafik hubungan nilai koefisien absorbsi bunyi terhadap frekuensi untuk 5 ketebalan ditampilkan pada Gambar 2. Dari Gambar 2 dapat dilihat pada semua sampel terjadi peningkatan nilai koefisien absorbsi bunyi dengan bertambah besarnya frekuensi. Namun pada frekuensi $1500 \mathrm{~Hz}$ terjadi penurunan nilai koefisien absorbsi bunyi. Hal ini sesuai dengan literatur dimana bunyi yang datang lebih banyak diserap daripada dipantulkan atau diteruskan pada frekuensi besar dengan panjang gelombang yang pendek.

Pori-pori pada sampel sangat ditentukan oleh perbandingan massa antara serat dan matriks. Komposisi matriks yang sedikit akan menyerap bunyi lebih baik daripada matriks dengan komposisi banyak karena gelombang bunyi yang datang akan diserap oleh material yang banyak mengandung pori-pori atau material dengan porositas yang tinggi sehingga gelombang bunyi lebih banyak diserap daripada dipantulkan. 


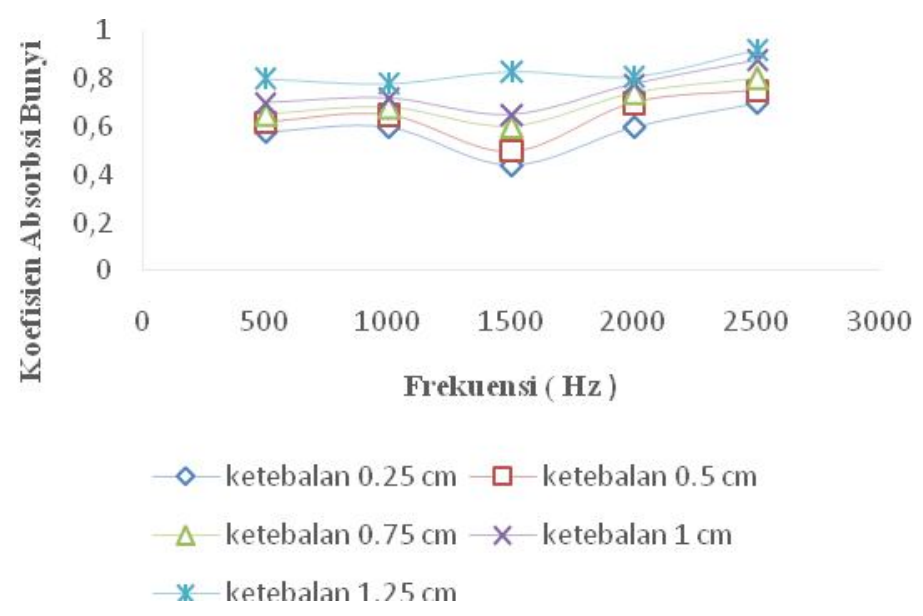

Gambar 2 Hubungan koefisien absorbsi $(\alpha)$ pada komposit serat sabut kelapa untuk beberapa ketebalan terhadap frekuensi

Dari Gambar 2 juga dapat dilihat pada kelima sampel uji bahwa semakin tebal sampel yang digunakan maka semakin besar pula nilai koefisien absorbsi bunyi. Hal ini disebabkan karena lamanya bunyi datang mengalami vibrasi di dalam pori-pori sampel.

\subsection{Hubungan Ketebalan Komposit Serat Sabut Kelapa terhadap Impedansi Akustik}

Nilai impedansi akustik dengan variasi ketebalan komposit serat sabut kelapa dan variasi frekuensi dapat dilihat pada Tabel 2. Dari Tabel 2 dapat dilihat bahwa nilai impedansi akustik mengalami peningkatan dengan bertambah ketebalan. Hal ini disebabkan karena impedansi akustik berbanding lurus dengan induktansi yang analog dengan massa. Nilai impedansi akustik tertinggi didapatkan pada ketebalan $1,25 \mathrm{~cm}$ sebesar 2,485 dyne.sekon $/ \mathrm{cm}$. Nilai impedansi akustik terendah didapatkan pada ketebalan $0,25 \mathrm{~cm}$ sebesar 0,569.

Tabel 2 Hubungan Ketebalan Sampel terhadap Impedansi Akustik

\begin{tabular}{cccccc}
\hline \multirow{2}{*}{ Frekuensi (Hz) } & \multicolumn{5}{c}{ Ketebalan / Impedansi Akustik } \\
\cline { 2 - 6 } & $\mathbf{0 , 2 5} \mathbf{~ c m}$ & $\mathbf{0 , 5} \mathbf{~ c m}$ & $\mathbf{0 , 7 5} \mathbf{~ c m}$ & $\mathbf{1 ~ c m}$ & $\mathbf{1 , 2 5} \mathbf{~ c m}$ \\
\hline 500 & 0,569 & 0,734 & 0,921 & 1,009 & 1,109 \\
1000 & 0,801 & 0,951 & 1,023 & 1,109 & 1,203 \\
1500 & 0,901 & 1,025 & 1,230 & 1,418 & 1,501 \\
2000 & 0,911 & 1,027 & 1,301 & 1,400 & 1,611 \\
2500 & 1,173 & 1,532 & 1,967 & 2,187 & 2,485 \\
\hline
\end{tabular}

Grafik hubungan nilai impedansi akustik terhadap frekuensi untuk 5 ketebalan ditampilkan pada Gambar 3. Semakin tebal sampel maka semakin tinggi pula nilai impedansi akustik. Berdasarkan Gambar 3, pada sampel uji terjadi peningkatan nilai impedansi akustik dengan bertambahnya frekuensi. 


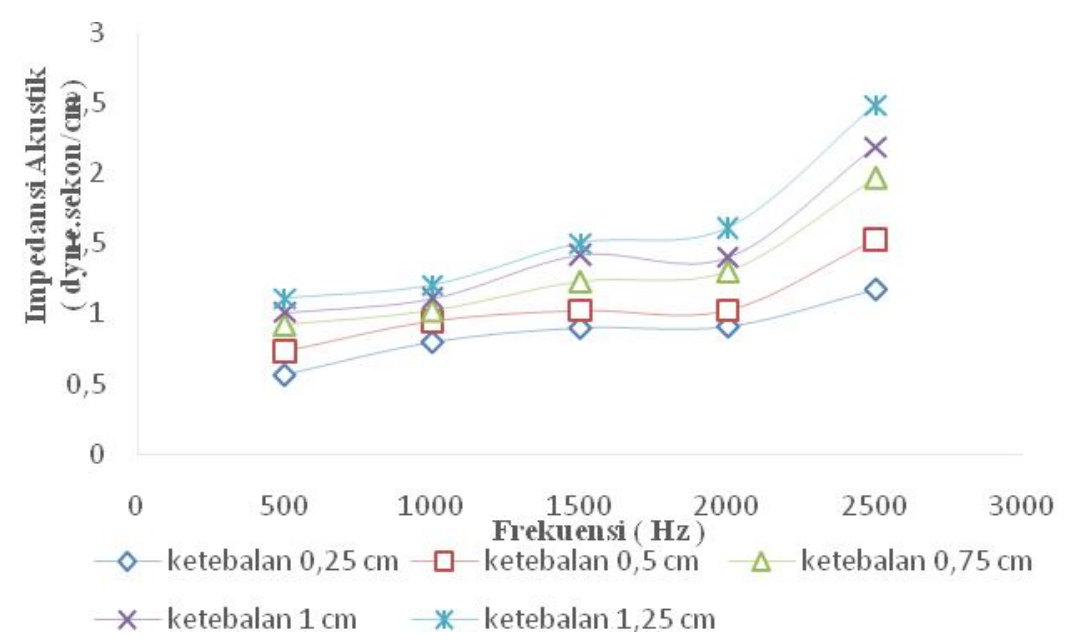

Gambar 3 Hubungan Ketebalan Komposit Serat Sabut Kelapa terhadap Impedansi Akustik

\section{KESIMPULAN}

Nilai koefisien absorbsi bunyi terendah sebesar 0,44 terdapat pada ketebalan $0,25 \mathrm{~cm}$ dengan frekuensi $1500 \mathrm{~Hz}$. Nilai koefisien absorbsi bunyi tertinggi sebesar 0,92 terdapat pada ketebalan 1,25 cm dengan frekuensi $2500 \mathrm{~Hz}$. Semakin tebal sampel maka semakin besar pula nilai koefisien absorbsi bunyi. Hal ini disebabkan karena gelombang bunyi pada frekuensi dengan panjang gelombang yang pendek lebih banyak bervibrasi melalui pori-pori yang ada pada sampel daripada dipantulkan

Nilai impedansi akustik terendah didapatkan pada ketebalan $0,25 \mathrm{~cm}$ sebesar 0,569 dyne.sekon/cm pada frekuensi $500 \mathrm{~Hz}$. Nilai dari impedansi akustik tertinggi 2,485 dyne.sekon/cm berada pada frekuensi $2500 \mathrm{~Hz}$ dengan ketebalan sampel 1,25 cm. Semakin tebal sampel maka semakin besar nilai impedansi akustik. Hal ini disebabkan oleh impedansi akustik berbanding lurus dengan induktansi dimana pada material akustik analog dengan massa.

\section{DAFTAR PUSTAKA}

Beranek, L., Acoustic Measurement (John Wiley \& Sons Inc, New York, 1949).

Bucur, V., Acoustic of Wood, 2nd Edition, (Springer: CRC Press 2006).

Doelle, E., Akustik Lingkungan ( Erlangga, Jakarta 1986).

Elkhateeb, A., dkk., Absorption Characteristics of Masjid Carpets (Elsevier, Saudi Arabia, 2016), hal 143-155.

Matthews, F.L. dan Rawlings, R. D, . Composite Material Engineering and Science ( Imperial College of Science Technology and Madicine, London 1993).

Puspitarini, Y., Koefisien Serap Bunyi Ampas Tebu sebagai Bahan Peredam Suara ( Jurnal Fisika Vol. 4 No. 2, November 2014,. Universitas Negeri Semarang 2014).

Ronald, F.G,, Principles of Composites Material Mechanics, ( McGraw-Hill Book Company, New York 1994).

Sari, P.N., "Pengukuran Karakteristik Akustik Ampas Singkong sebagai Bahan Penyerap Bunyi dengan Metode Tabung Impedansi Dua Mikrofon",Skripsi Universitas Semarang, 2016. 